Article

\title{
Technological Specificity, Transduction, and Identity in Media Mix
}

\author{
Alba Torrents \\ Independent Researcher, Barcelona 08001, Spain; albagtorrents@gmail.com
}

Received: 3 June 2018; Accepted: 16 July 2018; Published: 23 July 2018

\begin{abstract}
In this paper, I focus on the study of the relationships between technological specificity and media mix, focusing on how anime, as a visual medium, is connected to other media. There are two main aspects to this paper: the study of the complexities of the visual media milieu in the age of media mix, taking into account the technological materiality of different channels of production and consumption, and the study of the way these complexities must be approached. Taking materiality and information as the key aspects of the way specific objects in media are interconnected, I explore a question that has appeared recently in media studies: what is the right way to approach the relationships between media?
\end{abstract}

Keywords: media-mix; identity; materiality; technological specificity; transduction; anime

\section{Introduction}

In recent decades, the emergence of new strategies in the production and consumption of narrative fictions has changed the way people relates to cultural technical objects and to the narratives they enact. Some of them have to do with the interaction between different media.

In Textual Poachers: Television Fans and Participatory Culture (Jenkins 1992), Henry Jenkins described the expansion of a viewer culture in which fans were no longer passive consumers-if they had ever been. He was one of the first to use, in the turn of the millennium, the concept of "transmedia storytelling" ${ }^{1}$ to refer to the phenomenon where elements of a narrative spread across multiple media platforms. In recent decades, the label "cross-media storytelling" has also emerged to describe a specific transmedia strategy: while in transmedia proper, different stories occur in shared world that appears in multiple media, cross-media does not use strategies to expand a central narrative through multiple narrations, but redistributes one narrative through different platforms. Those phenomena have attracted the attention of scholars from different disciplines, and they have raised some methodological and epistemological challenges related to the interaction not only between media, but also between the disciplines that study them.

This discussion has had interesting ramifications in the world of Japanese media studies. In the last few years, a growing group of researchers have directed their attention to the study of the production and consumption of cultural products in the context of what has come to be known as media mix.

What is media mix? Media mix refers to a use of transmedia strategies where stories, worlds, and characters spread over different platforms. As it happens with cross-media storytelling, media-mix

1 Marsha Kinder used the term in 1991 to refer to franchises which use joint storytelling strategies across different media. Henry Jenkins uses the term for the first time in an article for Technology Review, "Transmedia Storytelling" (Jenkins 2003), in which he considers how the coordinated use of storytelling in different platforms can make the characters more attractive for the public. 
emerges from a single product of a single media and spreads through different media. However, the concept of media mix is used mainly in the context of Japanese cultural productions, and while most examples of "transmedia storytelling" tend to emphasize the narrative continuity between platforms, media mix is based instead in a principle of variation: in media mix, characters, elements of world construction, and specific tropes associated with a particular fiction are repeatedly used in different media as variations on the same idea, sometimes without any direct continuity. ${ }^{2}$

According to Marc Steinberg's definition in his book Anime's Media Mix: Franchising Toys and Characters in Japan,

The anime media mix within popular discourse refers to two intersecting phenomena: the translation or deployment of a single work, character, or narrative world across numerous mediums or platforms (also known as repurposing) and the synergetic use of multiple media works to sell other such works within the same franchise or group. (Steinberg 2012, p. 142)

In the book, Steinberg explores the connections and interactions between some Japanese cultural productions, including certain manga, anime, and video games; the characters used in these productions; and the toy market. These links were already explored by commercial producers in pre-war hits such as Norakurom, but they have had an especially important role in Japan's cultural industry since they consolidated on the 1960s. To inspect the history of these transmedia relationships and the way they evolved into what we now call media mix, Steinberg follows one particular thread of fiction: Tezuka's Astroboy. The choice is not arbitrary: the concept of media mix it was introduced precisely in the context of the 1960s, even though it would not become a buzzword until the 1980s (Steinberg 2012, p. viii).

The academic discourse on media mix is also closely entwined with the discourse on otaku culture. Although some anglophone ${ }^{3}$ researchers have recently entered otaku studies discussions, it is a field populated mainly by Japanese researchers and scholars, which in turn are, in many instances, deeply indebted to continental thinkers. In some aspects, otaku studies could be interpreted as the "Japanese equivalent" of media mix studies. ${ }^{4}$ The most prominent participants in the discussion are Eiji Ōtsuka, Hiroki Azuma, Tamaki Saitō, and Gō Itō. Although I will not discuss the works of these authors in depth, it is interesting to mention that they identify two main features of Otaku culture: the fragmentation of the narrative, and the increasing importance of characters (rather than the story itself) as items of consumption.

In this paper, I explore three issues concerning general ontological and methodological aspects of media mix. However, to enable some finer-grained perspective, at different points I focus on anime as an example how a specific medium integrates into media mix:

1. How does media mix affect the identity of its component media as a technical objects? Media mix implies a process of producing stories, characters, and worldviews in which different media are purposely included into the mix from the onset. It is based on seriality, not continuity. As a result, it raises questions that are particular to it and different to those suggested by other transmedia strategies, questions such as: what is at stake in divergent and convergent series of fictions? What

2 Kopylova's brilliant and comprehensive PhD thesis is a case studio on media mix focused on Gankutsuou: The Count of Monte Cristo (Kopylova 2016). In her thesis, Kopylova examines the case of Gankutsou as an emblematic example of media mix case where one story, The Count of Monte Cristo, originally written by Alexander Dumas, is adapted through different media platforms (there's an anime, mangas, and light novels).

3 In "Taking otaku theory overseas: Comics studies and Japan's theorists of cultural postmodern" (Brienza 2012), Casey Brienza analyzes the discourses of Japanese Otaku theorists and their differences with parallel anglophone developments, while in "From 'game-like realism' to 'imagination-oriented aesthetic': Reconsidering Bourdieu's contribution to fan studies in the light of Japanese manga and otaku theory" (Kacsuk 2016), Zoltan Kacsuk reviews the AMO (anime, manga, and otaku) Studies of these Japanese authors considering them in the light of theories exposed in the book Distinction by the French sociologist Pierre Bourdieu.

4 Kopylova devotes a chapter of her thesis to the relation between media mix and otaku studies (Kopylova 2016, pp. 65-72). 
acts as a basis for these divergence and convergence processes? And which kind of identity can a cultural product such as anime have in this context of variation?

2. How should we conceive media mix itself as a technical object? Is there such a thing as a specific "intermateriality" of media mix? While Japanese video games, anime, manga, and other media have become intertwined in media mix, each medium retains its own technical and narrative specificity, so the different materialities of each technical object are obviously very relevant when we want to approach their relationships. One question that arises as central is: is there such a thing as the specific "intermateriality" of a group of media?

3. What kind of methodological problems arise in the study of the materiality of media mix? Media mix is essentially hybrid: it is not only transmedia, but also transnational and transdisciplinary. In academia, it has been approached from sociological, economical, narratological, historical, aesthetical, and technical points of view. But, how can these different perspectives be put together in order to unearth the specificity of its object?

In order to look into these three issues, I will introduce some ideas extracted from Simondon's theories of individuation and the technical object. I will also apply some of the core ideas from Lamarre's book The Anime Machine.

In his book, Lamarre presents a theory of animation that provides an answer to the question "how should we read anime?", focusing on its technological specificity instead of treating animation as "just another text" Lamarre's proposal goes beyond presenting a list of relevant elements for the formal analysis of anime (lighting, color, sound, narrative, shooting, editing, etc.). He presents a content analysis based on the materiality of the moving image. The result is a book with an emphasis on how animation thinks technology, not on the representation of Japan in the anime.

\section{Identity in Media Mix: The Case of Anime}

As happens with its subject matter, media mix studies can be characterized as transdisciplinary, transnational, essentially hybrid. Media mix has been approached from sociological, anthropological, historical, and philosophical points of view (Steinberg 2012; Allison 2006; Condry 2013; Lamarre 2017). In turn, the identity of anime has been considered from an aesthetical point of view (Suan 2017), from a historical one (Clements 2013), and from a materialistic one (Lamarre 2009), but what about anime as a component of media mix?

When we consider anime as a medium whose narratives intertwine with other media, a fundamental question emerges: what constitutes anime's specific identity as a component of media mix? Although anime includes an ever changing diversity of genres, audiovisual styles, narrative techniques, animation techniques, character styles, and worldviews, they all tend to converge according to certain conventionalized patterns. To understand anime, then, we need to look at the way repetition and convergence phenomena, on the one hand, and variation and divergence phenomena, on the other, contribute to its identity. In mass-produced anime, certain patterns tend to be repeated in a recognizable manner, conforming to a unity of narrative and visual style that can be identified as typical of anime. However, considering anime as something homogeneous would be wrong, especially in the context of media mix theory.

The matter of the role of divergence and convergence in the constitution of anime as a medium can be approached on the basis of very different ontological notions of variation, repetition, and identity.

We have the Derridean (Derrida 1978) conception of identity and differentiation. Although in Derridean philosophy a copy can be said to be "without original", in the Derridean notion of "copy without original", difference and identity are thought to emerge through the very same process of "failed copying". One does not have any priority over the other: identity, which is always structurally incomplete, is founded at the same time and in the same act than difference

On the other hand, for Deleuze (Deleuze 1994) variation is secondary with respect to both identity and to the difference that founds it: variation is a difference that requires a prior identity, a difference 
that makes sense only if it is based on an already predetermined identity. In the Deleuzian model, there is an ontological priority of difference, but this ontologically primary difference is not a variation with respect to anything: there is no "original" of which there can be a divergent copy.

There are, then, two main ways to understand pattern variation and convergence in anime, and they follow different ontological logics. In some cases, the idea of variation implies a previous identity. If it is possible to execute a variation on a piece, it is precisely because the piece is previously "something", because it is already constituted in its identity. On the other view, it is variation itself that constitutes or "performs" the identity.

Stevie Suan is an academic who has been working on what constitutes anime's identity as a medium. Suan has explored the issue of anime's identity in an article called "Anime's Performativity: Diversity through Conventionality in a Global Media-Form" (2017). To Suan, anime's identity is a matter of convergence within a diverse activity, and his fundamental question concerns how anime can maintain this identity while continuously producing - at the same time and in the same process-variation and difference.

Put differently, how does anime maintain a relatively uniform aesthetic, and thus retain its identity, but continue to produce diversity and change over time? This is the aesthetic problem anime works through in the performance of the anime themselves. (Suan 2017, p. 66)

Suan's ontological stance on the identity of anime is based, in many aspects, on Butler's theory of performativity and, less explicitly, on Derridean deconstruction. For Butler, identity and difference are produced performatively. Every identity category is produced by acts of repetition that take place over time; identity is performative in the sense that it is produced in the acts themselves in which its variability and differentiation are shown, and therefore, it is in constant review. The same performative acts that establish identity also establish difference and variation.

To conceptualize anime in these global contexts, anime's identity can be considered as straddling the dynamic divisions between uniformity, repetition and the global, on the one hand, and diversity, variation and the local, on the other. As such, anime's media-form can be seen as produced through, using Judith Butler's [ ... ] turn of phrase, a 'stylized repetition of acts' that negotiates anime identity in each performative instance, working through the problematics of diversity and uniformity, multiplicity and unity. This problematic is invoked through the engagement of conventionalized elements and the technical processes/materiality of animation. In other words, anime's identity is constituted just as much by audio, visual and narrative conventions as the medium of animation they are performed in. These conventions, when performed, bring anime into being, producing 'acts of anime', so to speak: a 'doing' of anime. (Suan 2017, p. 67)

One of the main examples of a definition of anime's identity founded not only in variation, but in a more fundamental "animetic difference" can be found in Lamarre's work.

Many academics have devoted themselves to analyzing anime from a thematic point of view, but most have tended to ignore the very materiality of Japanese animation (Lamarre 2009), that is, the fact that it is a moving image. Lamarre, on the other hand, presents an analysis of the anime based on the materiality of the moving image, providing an exhaustive study of the technical aspects of animes of Miyazaki, Anno, and CLAMP, and adapting to their specificity:

I wish to highlight that the force of the moving image, which results from the mechanical succession of images, is the basic technological condition for animation. It is surely for this reason that many theories of animation gravitate toward philosophies that give ontological priority to movement over stillness, to process over structure, to becoming over being, and even to life over death. (Lamarre 2009, p. xviii) 
Lamarre believes that the specific materiality of the animation is fundamental to understand what they offer us from the thematic point of view. Not taking into account the way in which the anime thinks about its themes can lead to taking it as a passive object in which messages are merely transmitted or reproduced.

His proposal focuses, in contrast, on the analysis of animation as a technique of moving images. Lamarre highlights the technological specificity of anime as the way to read anime. Technological specificity takes into account the way anime is materially formed, the way the "animetic interval" works, that is, the movement between planes of image. In his book, Lamarre makes some comments about divergence and convergence in anime:

In keeping with this approach, I see recent developments in transmedia serialization not in terms of a break with animation but in terms of divergent series of animation unfolding from the animetic machine. Instead of breaks between eras or generations, I see divergent series that entail mutations and transformations, transitions and passages, in which different series remain on stage. Divergent series today crowd the scene. Indeed, even if they are somehow outdated or passé, the animations associated with Ghibli, Gainax, and CLAMP remain an important force, alongside a wide variety of anime-game series and other serial franchises. (Lamarre 2009, pp. 301-2)

According to Lamarre, we must focus on the materiality and technical specificity of anime, as it provides the context of emergence of these divergent series. Talking about anime without understanding its technical specificity is producing a collection of anecdotes.

Lamarre draws on Deleuzian ontology, according to which empirical experience is, first of all, an experience of pure difference, with categories coming only later. The more you capture the specific, the more you capture ontological difference. By looking at the material specificity of anime, Lamarre is approaching the difference that constitutes anime before any variation may occur.

In this sense, Suan's proposal bears a resemblance to Derridean ontology, and distances itself from the Deleuzian ontology used by Lamarre. The latter is in a position similar to Deleuze regarding his position on the ontological priority of the difference.

First and foremost, looking at technological determination reminds us that media convergence or product alliances are not inherent in the animetic interval or in the media associated with animation. We might use the term "media mix", because "mix" feels decidedly more neutral than "convergence" or "alliance". Yet I think it necessary to back up another step and consider, however schematically, what is at stake in starting with the divergent series that follow from the moving image. It is on the basis of divergent series that we can begin to look at how modes of production and distribution intersect with, and strive to capture, the animetic machine (Lamarre 2009, p. 302).

As I have already mentioned, repetition is not primary in Deleuze: it is presented as that which generates identity, but it is always considered as secondary, ontologically speaking, with respect to difference. Suan stands out from Lamarre in considering that animetic difference (new fashions or styles in the anime, new variations) appears after convention.

In a sense, Suan's proposal is less concrete than Lamarre's, but tries to be broader. Suan's approach does not take material specificity as a key element in answering to the question about what anime is. We only know that it is founded through repetition. Where Lamarre points to an "original" difference that is repeated in anime, Suan points to the mechanism of repetitive variation itself.

If we examine Suan's proposal from the point of view suggested by Lamarre, the following problem emerges: if the anime medium is taken as a "formal system", we can never understand in its concreteness the difference that founds it. When Lamarre analyzes the characteristic repetitions of anime, he finds specific material elements to be definitory of its identity. Those elements present a novelty that makes anime stand out from everything that is not anime. In Suan's performative serialization analyses, repetition itself constitutes the medium, while for Lamarre repetition is always the repetition of a difference of content. 


\section{Specificity and Transmateriality in Media Mix: Transduction between Media}

Separating medium and message in media is as problematic as separating form and content. In both cases, the two accompany each other: they are always in the process of becoming together.

Simondon's philosophical notion of information and his critique of the hylemorphic scheme can be illuminating to this respect (Simondon 2005, pp. 39-51). According to Simondon, it would be an epistemological error to consider the principle of individuation (that is, that which constitutes individuals as separate and unique), as something prior to the acquisition of form. If we describe form acquisition as mere abstract process, information loses its characteristic dynamism. To understand processes by which a technically mediated cultural object acquires its form, it is important to approach them in its very concretion, in its becoming. In animation, for instance, there is a very specific technical process by which certain physical, social, and technical elements are combined to form sequences of drawings in movement. This process is already complex for each medium, but in the case of media mix, there is an added layer of complexity: we need to know not only how a particular class of objects is physically, technically, and culturally informed, but also, how some meaningful elements can be transported from one medium to another and still retain their identity.

In his book The Anime Machine, Lamarre defends the thesis that the technical specificity of anime is crucial to understand what anime really is and how it thinks its subject matters. How about media mix? Is its technical specificity, and therefore its identity, reducible to that of the media that participate in it?

Conceiving the technical and material aspects of media mix from a Simondonian point of view allows us to interpret it as an object whose technicality is based on a transductive operation that materializes the relational aspects of a certain set of interactions between the human being and its milieu. According to Simondon, the primordial technical object is never a natural physical system, but rather a physical transduction of an intellectual system. It consists of a crystallized succession of applications of knowledge, and that is what constitutes its "artificiality". But for some degree of technical perfection to exist, the technical object has to gain distance from its operators and approach the kind of existence of natural objects: a necessary condition for this to occur is the presence of indeterminacy in the system that constitutes a device. This indeterminacy opens the technical object to the possibility of an open relationship with the world. In this sense, media mix can be understood not only as the crystallization of certain psychological social operations in a technical form, but also as an example of certain technical operations (those materially characteristic of each media) gaining a certain independence from its material conditions of emergence, from the questions they were originally supposed to answer.

However, if there is no merely abstract "content" that can be transported from one platform to another, we have to face another question: what is the specific intermateriality of this medium? How are the different media related to each other at a material level? The process by which media mix is constituted as such is not one of translation, but of transduction: an intertwining of different domains of reality that constitutes a new domain in itself. The specificity of media mix consists precisely in that the features of a certain technical specificity (of a particular thinking device) are transduced into others: the adaptation of "ideas" or "characters" from one medium to another is a process in which the materiality of both terms and of the process of adaptation itself has to be taken into account.

The idea of transduction underscores the processual aspect of reality and the existence of active relationships between all levels of reality, from the physical to the technical. In transduction, technology is not seen as a mere copy of the social: it relates both to it and to the physical world as interconnected but distinct realities. In any case, we see that, at all levels, there is always a propagation and amplification of the structures themselves, and that this propagation reveals the individual as a relational being.

Simondon conceives reality as a system that cannot be reduced to a collection of terms, that is, one in which relations are as real as terms. In fact, relations are prior to terms: they constitute them. Transduction lets us conceptualize the real relations between different domains of reality, by which 
they come to be and to interact to each other in the same unique movement. An individual and an environment constitute a system that evolves together: individuation is not exclusive of the individual or the medium, but operates transductively in both.

Simondon deals with technological individuation according to these parameters. According to Simondon, a genetic interpretation of the relationship between human beings and the world is necessary to understand technical objects. Technical reality does not constitute an independent domain, but is - in fact-one of the first forms of relationship between man and the world. Although the emergence of technicality appears the bring discontinuity between man with the world, this discontinuity does not erase a previous ontological continuity. Thus, although the genesis of a particular technical object could be described by itself, its meaning cannot be unearthed without looking at its genesis, that is, at its relationships with other levels of reality. For example, in the case of the media mix, we can describe how that particular anime or video game was made without taking into account anything else than itself as a technical object, but that leaves something important about its meaning in the shadows. For Simondon, we cannot understand technicality only by looking at technical objects because technicity is something that surpasses them. Technical objects result from an objectivation of technicality, but technicity is not exhausted in objects nor totally contained in them.

This technicity that is not exhausted in objects is also what keeps them in active relationships. The products (anime, manga, videogames, light novels) included in media mix are both technical objects and an aesthetic objects and, in this sense, they are forms of collective expression embodied in a technical gesture. They are transductions of certain psychological and collective structures into physical systems, social gestures crystallized in technical objects. We situate ourselves in a materialist perspective: thought occurs in the interaction with reality that is always material. Matter shapes thought and thought shapes matter. We must understand media mix as a technical milieu in which objects are shaped meaningfully.

We can think of a variety of examples. For example, some features of the anime character Naruto are derived from the conditions of production and consumption of the Naruto manga. In an interview, Kishimoto commented that he changed Naruto's original goggles for a headband because it was too tiring to draw them every week, and it took a lot of effort from the animators to animate three-dimensional googles (Gallow 2017).

Another classic example is that of the relationship between robot anime and the toy market. Some features of the super robot genre that started with Mazinger $Z$ cannot be explained without reference to the robot figure market. With Mazinger $Z$, products quickly racked up record-breaking sales, forming a cornerstone of the robot anime success story. Its success not only meant a long history of making toys related to the world of robot anime, it also made it clear that viewers were potential consumers of these toys. In any case, Mazinger $\mathrm{Z}$ toys were part of a second generation of toys in which the previous tin robot toys had been abandoned. As Schodt says:

Bandai, Japan's most famous robot toy maker, had made tin versions of Mighty Atom in 1963, but in 1974 it began manufacturing a toy robot that replicated Mazinger Z-artist Go Nagai's giant "drivable" robot warrior that thrilled young Japanese boys in comics and animation Company designers made the toy "realistic." It could not only pose, but with plastic parts and a die-cast zinc metal alloy body, had a feeling of weight and power. (Schodt 2010, chp. 5, sct. 3)

The different markets and distribution technologies associated with each medium can also have a significant impact. Seisakuinkai (production committees) are crucial in media mix production. In these committees, companies gather together in order to decide the transmedia strategies for a specific franchise. As a result, the materiality of the distribution channel has a direct impact in creative decisions form the onset. In addition to this, some distributors (such as pirating sites) make unexpected changes to the product which enhances media mix's logic of variation. 


\section{Transdisciplinary: Methodological Challenges of Media Mix}

So far, I have addressed the issues of identity in anime in the context of media mix, and the specific identity of media mix itself. In the first part, I have dealt with the role of divergence and convergence in constituting a medium: according to Lamarre's proposal, anime's identity should be found in its specificity, and its specificity it is something which can be found in its technical and material operations. In the second part, I have discussed the importance of specificity and materiality in media mix as well. To conduct good research on media mix, what is needed is a good knowledge of its material and technical specificity. Given the fact that media mix studies have to deal with different media, it is appropriate to say that they have to be interested in how information is transduced form one milieu to another, and in how this operation affects their different materialities. The technical specificity of media mix implies a transmateriality, but how does this affect both media mix studies and particular media studies, such as anime studies?

In media mix, some technological features of a medium are somewhat transduced into another. It is no longer enough, for instance, to understand animation technology to understand anime; you also have to understand the technology of another type of media (i.e., you have to understand how a toy is produced to understand how animation is produced, or understand the relationship between a manga and an anime, etc.).

To consider media mix according to its material configurations is to consider what processes and technical operations are carried out by this kind of object in order to enact meaning. If we turn again to Simondon's criticism of Aristotelian hylomorphism and its influence, we can observe that his criticism focuses precisely in the fact that hylomorphism and its descendants conceive the technical processes by which materials acquire new shapes in a way that is overly abstract and static. That is, matter and form are never separate: they join together, and they should always be thought of together in their relationships, not separately. In the first chapter of L'individuation (Simondon 2005, pp. 39-67), using the example of the manufacturing process of a brick, Simondon shows that the technical operation by which an object acquires a particular shape is always a dynamic relationship between a prepared material and a materialized form, a process in which the presence in a system of a certain amount of potential energy is a necessary condition.

The epistemological mistake pointed out by Simondon consists in considering the information processes (i.e., the processes by which matter is informed) in a technical operation only from the viewpoint of inductive logic, which leads to producing a universal abstraction in which the inherent dynamics of technical becoming are left completely out of sight. It is crucial to stress here the importance of the (material) specificity of the technical operation. Simondon turns his criticisms against those approaches to the technical object that do not take into account its genesis and its formation processes-i.e., that consider the object only as a product, forgetting its production completely or treating it as a mere epiphenomenon. I think it is possible to transport the main idea expressed in Simondon's analysis of the production of a brick to the production of anime as a technical object in the media mix context. This helps us avoid approaching it from an overly abstract epistemological view, which would reduce it to a mere product and severely obscure an important part of its material specificity. In my research, I have been focusing on the materiality of the technical operation that constitutes anime, particularly its dynamism: taking into consideration the material specificity of anime as a technical object implies not only considering certain formal and narrative structures in which meaning is produced, but also looking at how they emerge through time in a particular process involving the movement of images. More importantly, it stresses the importance of media mix as a medium in which different materialities are involved.

When talking about media mix, one important methodological issue is how we approach the specific way elements are adapted from one medium to another, or in some cases, how they are conceived "intermediatically" (but always in reference to a given set of media). All too often, there is a tendency to look at it in an excessively abstract way. My approach stresses precisely that it is due to the fact that relation has an ontological priority to individuals that we can talk about media mix. It is 
also the way we have to examine it methodologically. To study media mix, we need experts in the technical specifics of each medium (narratologist, ludologists, musicologists, etc.), but we also need researchers focused on specific transduction processes (adaptation studies), and researchers who study the concrete and complex patterns in which the relations between different media become a milieu and, in a sense, a driving force in productive processes.

Funding: This research received no external funding.

Acknowledgments: I would like to thank the reviewers for their insightful comments, and my husband for his personal and intellectual support.

Conflicts of Interest: The author declares no conflict of interest.

\section{References}

Allison, Anne. 2006. Millennial Monsters. Japanese Toys and the Global Imagination. Berkeley, Los Angeles and London: University of California Press, ISBN 0-520-22148-6.

Brienza, Casey. 2012. Taking otaku theory overseas: Comics studies and Japan's theorists of postmodern cultural consumption. Studies in Comics 3: 213-29. [CrossRef]

Clements, Jonathan. 2013. Anime: A History. London: Palgrave, ISBN 978-1844573905.

Condry, Ian. 2013. The Soul of Anime: Collaborative Creativity and Japan's Media Success Story. Durham and London: Duke University Press, ISBN 978-0-8223-9755-7.

Deleuze, Gilles. 1994. Difference and Repetition. New York: Columbia University Press, Originally published as 1968. Différence et Répétition. Paris: Presses Universitaires de France. ISBN 0-231-08158-8.

Derrida, Jacques. 1978. Writing and Difference. Chicago: The University of Chicago Press, Originally published as 1967. L'écriture et la difference. Paris: Éditions du Seuil. ISBN 978-0-8223-9755-7.

Gallow, Salim. 2017. Naruto Creator Reveals Why He Created Village Headbands. Posted by Salim Gallow. October 26. Available online: http:/ / otakukart.com/animeblog/2017/10/26/kishimoto-reveals-why-hecreated-village-headbands/ (accessed on 11 July 2018).

Jenkins, Henry. 1992. Textual Poachers: Television Fans and Participatory Culture. Abingdon: Routledge, ISBN 978-0415905725.

Jenkins, Henry. 2003. Transmedia Storytelling. Moving characters from books to films to video games can make them stronger and more compelling. Available online: https://www.technologyreview.com/s/401760/ transmedia-storytelling/ (accessed on 3 June 2018).

Kacsuk, Zoltan. 2016. From "Game-like Realism" to the "Imagination-oriented Aesthetic": Reconsidering Bourdieu's Contribution to Fan Studies in the Light of Japanese Manga and Otaku Theory. Kritika Kultura 26: 274-92. [CrossRef]

Kopylova, Olga. 2016. Media Mix as Adaptation: With Maeda Mahiro's Gankutsuō as an Example. Ph.D. dissertation, Kyoto Seika University, Kyoto, Japan.

Lamarre, Thomas. 2009. The Anime Machine. A Media Theory of Animation. Minneapolis and London: University of Minnesota Press, ISBN 978-0816651559.

Lamarre, Thomas. 2017. The Anime Ecology. A Genealogy of Television, Animation and Game Media. Minneapolis and London: University of Minnesota Press, ISBN 978-1517904500.

Schodt, Frederik L. 2010. Inside the Robot Kingdom: Japan, Mechatronics, and the Coming Robotopia. [Kindle DX version]. San Francisco: JAI2.

Simondon, Gilbert. 2005. L'individuation à la lumière des Notions de Forme et d'information. Grenoble: Éditions Jérôme Millon. Originally published 1964. Paris: PUF. ISBN 2-84237-181-6.

Steinberg, Marc. 2012. Anime's Media Mix: Franchising Toys and Characters in Japan. Minneapolis and London: University of Minnesota Press, ISBN 978-0816675500.

Suan, Stevie. 2017. Anime's Performativity: Diversity through Conventionality in a Global Media-Form. Animation 12: 62-79. [CrossRef]

(C) 2018 by the author. Licensee MDPI, Basel, Switzerland. This article is an open access article distributed under the terms and conditions of the Creative Commons Attribution (CC BY) license (http://creativecommons.org/licenses/by/4.0/). 